\title{
SHM for informed management of civil structures and infrastructure
}

\author{
Maria Pina Limongelli ${ }^{1}$
}

Published online: 22 September 2020

(c) The Author(s) 2020

Structural health monitoring (SHM) can be seen as a process that transforms data collected on the structure into actionable information for integrity management. The design and operation of monitoring systems are driven by the decision problem that the information is intended to support. Maintenance of existing structures is currently a compelling problem worldwide: infrastructure dating back to the 1950s and the 1960s of the last century are near, or even beyond, the end of their design lives. Due to increased traffic loads, deterioration and maintenance backlogs they operate under conditions deviating from original design assumptions. The events related to the recent collapses of bridges in Italy tragically highlighted the compelling need to improve the reliability of aging transport infrastructure. Effective maintenance interventions are needed to increase safety and to reduce losses of functionality and related consequences. Furthermore, natural hazards such as earthquakes or floods create emergency conditions that must be managed efficiently to reduce downtime and service interruption.

Structual health monitoring involves data collection, transmission, processing, and interpretation. The information extracted from data describes the onset or the evolution of possible damages, defects and deterioration processes and quantifies the actions the structure is required to withstand.

This information plays a key role in the structure life cycle integrity management, offering the possibility to reduce the uncertainty affecting the structural condition and to build predictive models of the future structural performance. Decisions about the optimal actions, needed to keep the structure at the desired level of functionality, can be greatly improved thanks to the reduction of uncertainty that affects reliability assessment.

In this respect, it is worth noting that SHM by itself does not improve the structural reliability. The role of SHM is

Maria Pina Limongelli

mariagiuseppina.limongelli@polimi.it

1 Department of Architecture, Built Environment and Construction Engineering, Politecnico di Milano, Milan, Italy rather to provide information that reduces the uncertainties related to structural performance. This enables a more accurate and precise assessment of the structural reliability, leading to an improved selection of optimal maintenance interventions.

Despite the importance of SHM as a decision support tool, research in this field is sometimes framed and bounded in the data collection and processing framework. The connection between the information provided by monitoring and data interpretation for the decision making has not been always evident. The reason probably lies in the cross-sectoral nature of the topic that involves experts in the two connected, yet distinct, domains of SHM and decision making. The aim of this special issue is to highlight the importance of this connection.

Several research groups worldwide answered to the call for papers launched in October 2019. The contributions tackle different decision pertaining to infrastructure maintenance and emergency management. The papers also cover the several phases of the data management process that are necessary to transform the structural response in actionable information. Key issues, recent advances, and emerging applications in the field of SHM supported integrity management are extensively reported. Furthermore, some of the gaps that limit the diffusion of SHM are discussed.

Drones equipped with high-resolution cameras and scanners can perform precise inspections and have already been used in some countries for bridge inspections. Image processing of data collected by unmanned aerial vehicles (UAV) for maintenance purposes is the topic of the paper by Potenza et al. [1]. The authors propose a technique for data processing based on the use of color-based image processing. The aim is to identify and quantify superficial extensive defects not characterized by a specific shape: paint absence, efflorescence, and vegetation on structural elements.

One of the main issues in the research field of SHM is the validation on real structures of the algorithms used to retrieve information from measured data. The number of monitored structures is still quite low and, due to economic constraints, they are usually instrumented with a small 
number of sensors. Besides this, many of the instrumented structures have never experienced damage or the relevant data are not always freely available for research purposes. For all these reasons, the SHM technologies proposed in the literature are often verified using numerical models or scaled laboratory specimens with simulated damage. These conditions eliminate several sources of uncertainty that can severely affect results. This is the reason why tests on full-scale structures with active degradation processes and damages are particularly interesting and useful for research purposes. In their paper, Ye et al. [2] studied a 30-year-old highway bridge that had exhibited multitude of performance deficiencies. The bridge is called the 'Nightmare bridge', due to the many types of interdependent deterioration and damage-related issues. In this article, the authors critically compare several techniques for data collection, highlighting the pros and cons of each one of the methods. Sensing, imaging, traffic-induced or controlled excitation, as well as controlled load testing were assessed and compared in this article. In addition, simulation and processing techniques such as finite element (FE) modeling, parameter identification, and other tools in the realm of information technology were also critically examined in the article.

A further application of SHM to a real large-scale structure is presented in the article by Oliveira and Alegre [3]. The paper is focused on the experience gathered since 2008 through the monitoring of the $132 \mathrm{~m}$-high Cabril arch dam. Data collected from the structure for maintenance and emergency management were processed by an automated system that promptly detects deviations from the reference states, simulated by a finite element model. The system also automatically detects seismic motions and is able to distinguish them from operational vibrations for emergency management purposes.

The purpose of installing a monitoring system for emergency management is to obtain real-time, informed, and accurate assessment of the structural functionality after a disruptive event. This requires a focused choice of the performance indicators that must be extracted from data and the definition of thresholds corresponding to the required performance levels. In the paper by Roohi and Hernandez [4], a probabilistic measure of the thresholds of the interstory drift is proposed and integrated into a decision-making framework for the post-earthquake assessment of buildings.

Post-earthquake emergency management is also the focus of the contribution of Miraglia et al. [5]. Their work involves parametric nonlinear identification method and damage indicator for the estimation of damage in masonry structures. The approach is validated using signals recorded on a strategic building during the L'Aquila earthquake in 2009.

Prognosis of future performance requires, beyond information about the structural condition, also the forecast of future actions. The probabilistic distribution of the traffic loads can be characterized using repeated measures collected through devices that weigh vehicles in motion (WIM) on a bridge. In the paper by Žnidarič and Kalin [6], measurements carried out using a WIM device were used to monitor the influence lines of bridges and to evaluate performance indicators to support maintenance decision making.

Besides directly supporting management activities, SHM data can provide information for code calibration. The paper by Sawicki and Brühwiler [7] reports the results of 28-month-long monitoring of a slab portion of the Chillon viaducts in Switzerland, using strain gauges and thermocouples. The results of these experimental campaigns show that the simplified method, commonly used to calculate the fatigue stress, is highly conservative and leads to overestimation of structural actions. The authors also provide recommendations for analyzing both traffic and thermal-induced stresses, which were validated by experiments.

Another contribution on the use of SHM to improve the understanding of specific structural performance and to support design codes is contained in the paper by Kašpárek et al. [8]. The paper presents the results of long-term monitoring in studying the interaction between the railway track and bridge on a 100-m-long arch bridge with a steering bar system. Based on the monitored behavior of the track and the bridge during the daily temperature cycles and the train crossings, recommendations corresponding to the optimal configuration for the bridge monitoring system were proposed.

Despite a great amount of research and number of successful applications, permanent monitoring systems are still preferably installed only on strategic or landmark structures. One issue that challenges large-scale implementation of these techniques pertains to the uncertainty in estimating the return on investment before their implementation. The concept of Value of Information from the pre-posterior Bayesian decision analyses technique provides a theoretical base to tackle this issue. In the paper by Giordano et al. [9], this approach is applied to support the cost/benefit analyses of a scour monitoring system for emergency management. The value of information for structural integrity assessment is also the topic of the contribution by Honfi et al. [10]. The authors demonstrate the increase of the expected utility that can be obtained through successive condition assessments. In this study, the value of the information added by successive assessment, with respect to single choice decisions, increases with damage severity and structural importance.

All the ten papers in this special issue have been an interesting and informative reading for me. I am convinced that this selection will provide a valuable source of information and inspiration for researchers, practitioners, and students interested in SHM for informed management of civil structures and infrastructure. 
I wish to thank all the authors who submitted their works and the colleagues who dedicated time and effort to review them.

The guest editor

Prof. Dr. Maria Pina Limongelli

Funding Open access funding provided by Politecnico di Milano within the CRUI-CARE Agreement.

Open Access This article is licensed under a Creative Commons Attribution 4.0 International License, which permits use, sharing, adaptation, distribution and reproduction in any medium or format, as long as you give appropriate credit to the original author(s) and the source, provide a link to the Creative Commons licence, and indicate if changes were made. The images or other third party material in this article are included in the article's Creative Commons licence, unless indicated otherwise in a credit line to the material. If material is not included in the article's Creative Commons licence and your intended use is not permitted by statutory regulation or exceeds the permitted use, you will need to obtain permission directly from the copyright holder. To view a copy of this licence, visit http://creativecommons.org/licenses/by/4.0/.

\section{References}

1. Potenza F, Rinaldi C, Ottaviano E, Gattulli V (2020) A robotics and computer-aided procedure for defect evaluation in bridge inspection. J Civ Struct Health Monit. https://doi.org/10.1007/ s13349-020-00395-3

2. Ye S, Lai X, Bartoli I, Aktan AE (2020) Technology for condition and performance evaluation of highway bridges. J Civ Struct Health Monit 10(5):573-594. https://doi.org/10.1007/s13349-02000403-6
3. Oliveira S, Alegre A (2020) Seismic and structural health monitoring of Cabril dam. Software development for informed management. J Civ Struct Health Monit. https://doi.org/10.1007/s1334 9-020-00425-0

4. Roohi M, Hernandez EM (2020) Performance-based post-earthquake decision making for instrumented buildings. J Civ Struct Health Monit. https://doi.org/10.1007/s13349-020-00416-1

5. Miraglia G, Lenticchia E, Surace C, Ceravolo R (2020) Seismic damage identification by fitting the nonlinear and hysteretic dynamic response of monitored buildings. J Civ Struct Health Monit. https://doi.org/10.1007/s13349-020-00394-4

6. Žnidarič A, Kalin J (2020) Using bridge weigh-in-motion systems to monitor single-span bridge influence lines. J Civ Struct Health Monit. https://doi.org/10.1007/s13349-020-00407-2

7. Sawicki B, Brühwiler E (2020) Long-term strain measurements of traffic and temperature effects on an RC bridge deck slab strengthened with an R-UHPFRC layer. J Civ Struct Health Monit. https ://doi.org/10.1007/s13349-020-00387-3

8. Kašpárek J, Ryjáček P, Rotter T, Polák M, Calçada R (2020) Longterm monitoring of the track-bridge interaction on an extremely skew steel arch bridge. J Civ Struct Health Monit. https://doi. org/10.1007/s13349-020-00389-1

9. Giordano PF, Prendergast LJ, Limongelli MP (2020) A framework for assessing the value of information for health monitoring of scoured bridges. J Civ Struct Health Monit. https://doi. org/10.1007/s13349-020-00398-0

10. Honfi D, Björnsson I, Ivanov OL, Leander J (2020) Informed successive condition assessments in bridge maintenance. J Civ Struct Health Monit. https://doi.org/10.1007/s13349-020-00415-2

Publisher's Note Springer Nature remains neutral with regard to jurisdictional claims in published maps and institutional affiliations. 